
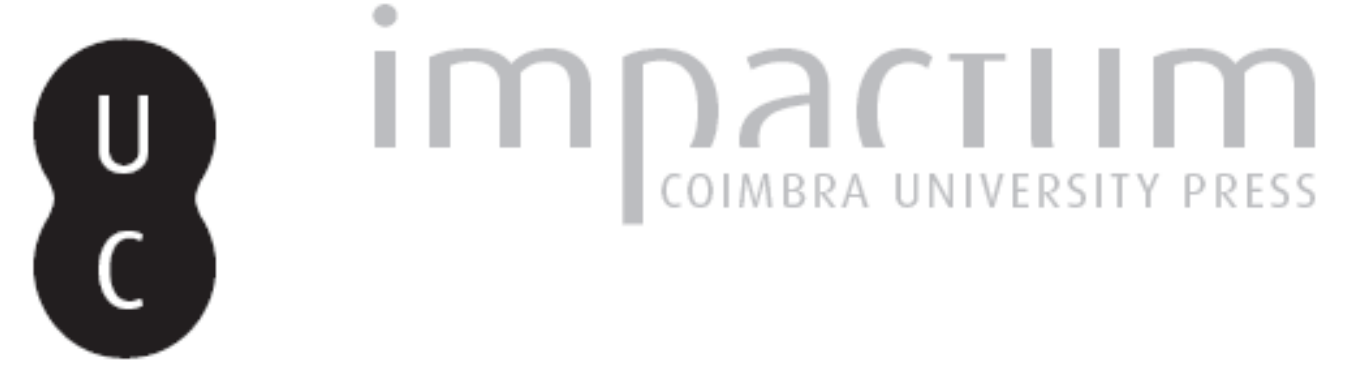

\title{
Contributos para a compreensão da evolução e dos valores das formas de cortesia voi e vostra signoria até ao século XVI
}

Autor(es): Mioni, Lino

Publicado por: Imprensa da Universidade de Coimbra

URL persistente:

URI:http://hdl.handle.net/10316.2/42641

DOI:

DOI:https://doi.org/10.14195/0870-8584_2_7

Accessed : $\quad$ 26-Apr-2023 12:35:15

A navegação consulta e descarregamento dos títulos inseridos nas Bibliotecas Digitais UC Digitalis, UC Pombalina e UC Impactum, pressupõem a aceitação plena e sem reservas dos Termos e Condições de Uso destas Bibliotecas Digitais, disponíveis em https://digitalis.uc.pt/pt-pt/termos.

Conforme exposto nos referidos Termos e Condições de Uso, o descarregamento de títulos de acesso restrito requer uma licença válida de autorização devendo o utilizador aceder ao(s) documento(s) a partir de um endereço de IP da instituição detentora da supramencionada licença.

Ao utilizador é apenas permitido o descarregamento para uso pessoal, pelo que o emprego do(s) título(s) descarregado(s) para outro fim, designadamente comercial, carece de autorização do respetivo autor ou editor da obra.

Na medida em que todas as obras da UC Digitalis se encontram protegidas pelo Código do Direito de Autor e Direitos Conexos e demais legislação aplicável, toda a cópia, parcial ou total, deste documento, nos casos em que é legalmente admitida, deverá conter ou fazer-se acompanhar por este aviso.

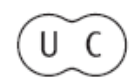




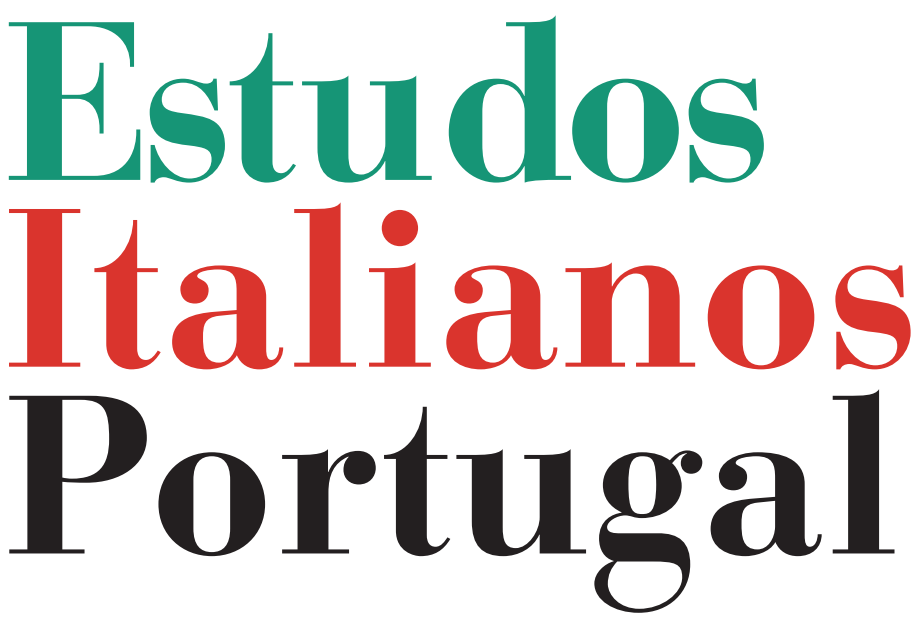

Instituto

Italiano

de Cultura

de Lisboa

Nova Série

$\mathbf{N}^{\mathbf{0}} 2$ 


\section{CONTRIBUTOS PARA A COMPREENSÃO DA EVOLUÇÃO E DOS VALORES DAS FORMAS \\ DE CORTESIA VOIE VOSTRA SIGNORIA ATÉ AO SÉCULO XVI}

LINO MiOni*

Os estudos SOBRE O USO das formas de cortesia usadas no século XVI em Italiano têm chegado a conclusões diversas ao longo dos anos. Um dos primeiros estudos sobre este assunto foi Tu, Voi, Lei. Etudes des pronomes allocutoires italiens, publicado por Camille Grand em 1930. Grand aborda a existência de duas formas de cortesia no século XVI: o voi e o Vostra Signoria e salienta que as duas formas podem ser usadas num texto para se dirigir à mesma pessoa. A co-ocorrência das duas formas traz como consequência um problema de natureza morfológica. Voi aparece sempre com elementos morfológicos de segunda pessoa plural, enquanto que Vostra Signoria, quando usado como sujeito, co-occorre com elementos morfológicos de terceira pessoa do singular. Utilizar uma forma ou a outra é, de acordo com este autor, uma escolha de alguma forma arbitrária, do próprio autor: "La seul règle que prédomine pendant tout le $\mathrm{XVI}^{\mathrm{e}}$ siècle fut le caprice ou le bon plaisir de chaque écrivain. " (Grand

* Lino Mioni é natural de Itália. Concluiu o Mestrado em Estudos da Linguagem e da Cognição na Universidade Nova de Lisboa em 2003, e o M.A. em Italiano na Ohio State University em 2005 com uma tese sobre o uso das formas de cortesia no Carteggio de Giovan Battista Giraldi Cinzio. Lecciona Italiano no Conservatório de Música de Coimbra e na Faculdade de Letras da Universidade de Coimbra. Tem em preparação um curso de pronúncia e dicção de Italiano para cantores.

Est.Ital.Port., n.s., 2, 2007: 117-133 
1930:66). Mesmo assim, o autor reconhece que a utilização de uma forma ou de outra não é completamente casual.

No seu Strutture allocutive reverenziali in italiano, Niculescu (1974) rejeita liminarmente a ideia proposta por Grand e afirma que os dois pronomes são "distribuiti in strati socioculturalmente ben definiti” (1974:109) acrescentando que as duas formas respeitam regras que "escludono il causale o l'errore” (1974:109). Porém, a proposta de Niculescu não está isenta de contradições pois, tal como ele mesmo reconhece, as duas formas podem aparecer num mesmo texto.

Também Migliorini, no seu artigo I primordi del Lei (1957:187-196), analisa o problema da coexistência das duas formas de cortesia ao longo do século XVI. Sublinhando que é possível dirigirmo-nos a um interlocutor usando o voi e a segunda pessoa do plural, ou com um título honorífico que indica uma qualidade abstracta, como Vostra Signoria, seguido de elementos morfológicos de terceira pessoa singular, Migliorini explica o uso das duas formas afirmando que "l'accordo con la terza persona dura sino a una pausa importante: poi ricomincia il voi" (1957:189). A explicação parece interessante, mas o que é problemático é o facto de Migliorini não definir o que entende por uma pausa.

Nenhuma das análises mencionadas parece enfrentar nem resolver o problema da possível co-ocorrência das duas formas de cortesia, durante um determinado período, e sobretudo não explica a co-ocorrência das duas formas num mesmo texto e visando um mesmo interlocutor.

\section{As formas de cortesia em Italiano}

As formas de cortesia podem ser definidas como "words or linguistics expressions that speakers use to appeal directly to theis addressees" (Jucker \& Taavitsainen 2003:1). Neste sen- 
tido, as formas de cortesia fazem parte daqueles "aspects of language structure that encode the social identities of the participants, or the social relationship between them, or between one of them and persons or entities referred to" (Levinson 1995:89)

O falante pode dirigir-se ao seu interlocutor de modo formal ou informal e o grau de formalidade usado pode ser expresso através de diferentes elementos: morfemas verbais, pronomes, possessivos, e elementos de concordância (cfr. Jucker \& Taavitsainen 2003:1).

De uma forma geral, nas línguas românicas o nível de formalidade é conferido sobretudo por elementos pronominais e por elementos de morfologia verbal.

Ao dirigirmo-nos a um interlocutor singular, em Italiano, a diferença entre dare del tu o dare del Lei materializa-se na utilização de elementos pronominais e de morfologia verbal de segunda pessoa do singular, no primeiro caso, e de terceira pessoa singular, no segundo. ${ }^{1}$

Em Italiano, é permitida a omissão do pronome de sujeito, sendo possível reconhecer o nível de formalidade usado numa troca dialógica através da análise de elementos de morfologia verbal. $\mathrm{Na}$ ausência de elementos de morfologia verbal ou de pronomes, o nível de formalidade pode ser reconhecido através de outros elementos, como em (1) onde $\mathrm{o}$ adjectivo possessivo nos permite reconhecer o diferente nível de formalidade.

(1) Ecco il tuo libro! / Eis o teu livro!

Ecco il Suo libro! / Eis o seu livro!

${ }_{1}$ Quando nos dirigimos a mais do que um interlocutor, o voi seguido de elementos morfológicos de segunda pessoa plural é usado tanto em situações formais como informais enquanto que a utilização de Loro, seguido de elementos morfológicos de terceira pessoa do plural, é realizado em situações de elevada formalidade. 
No Italiano contemporâneo, em caso de ausência de elementos de morfologia verbal, de pronomes e de adjectivos possessivos, o nível de formalidade pode ser veiculado através da utilização de elementos nominais tal como em (2) onde a segunda frase é claramente de um nível de formalidade superior ao da primeira, devido à presença de um substantivo, professore, indicativo de uma posição social superior do interlocutor relativamente ao falante.

(2) Buon giorno, mamma! / Bom dia, mãe!

Buon giorno, professore! / Bom dia, professor!

Como vimos, também elementos nominais podem ser usados quando nos dirigimos ao nosso interlocutor. No Italiano contemporâneo, estes elementos nominais são maioritariamente usados como vocativos, ainda que no passado nem todas as formas nominais tenham sido usadas exclusivamente com função de vocativo. Esta utilização, embora rara, ainda pode ser encontrada actualmente. No exemplo (3), citado por Renzi (1995:356), um empregado de mesa dirige-se a um cliente utilizando um elemento nominal, il signore, como sujeito da frase em vez de usar o pronome de cortesia Lei. Dado que nome e pronome não podem co-occorer, o elemento nominal não é um vocativo.

(3) Il signore desidera? / O senhor, deseja?

Por outro lado, o mesmo empregado poderia ter usado o pronome de cortesia Lei e o mesmo elemento nominal (que, neste caso aparece sem o artigo definido) mas com função de vocativo, como em (4).

(4) Signore, (Lei) desidera? / Senhor, o que deseja?

O nível de formalidade escolhida por um falante ao dirigir-se ao seu interlocutor pode ainda ser veiculado por fenó- 
menos de concordância. ${ }^{2}$ Em contextos informais, os adjectivos em acepção predicativa e os particípios passados de verbos ergativos concordam em género com o interlocutor: em (5) o interlocutor é masculino e em (6) é feminino.

(5) Paolo, (tu) sei italiano ? / Paolo, (tu) sei andato al cinema ieri? Paolo, (tu) essere-2 $2^{a}$ sing italiano-masc-sing? / Paolo, (tu) essere$-2^{\mathrm{a}}$ sing ido-masc-sing PP Adv?

Paolo, és italiano? / Paolo, foste ao cinema ontem?

(6) Paola, (tu) sei italiana a ? Paola, (tu) sei andata al cinema ieri?

Paola, (tu) essere-2 $2^{\mathrm{a}}$ sing italiano-fem-sing? / Paola, (tu) essere$-2^{\text {asing }}$ ido-fem-sing PP Adv?

Paola, és italiana? / Paola, foste ao cinema ontem?

A situação é análoga em contexto formais na presença de adjectivos predicativos como podemos ver em (7):

(7) Paolo, (Lei) è italiano? / Paola, (Lei) è italiana? Paolo, (Lei) essere- $3^{\text {a }}$ sing italiano-masc-sing? / Paola, (Lei) essere-3 ${ }^{\text {a }}$ sing Italian-fem-sing?

No entanto, a concordância do particípio passado pode variar na presença de verbos ergativos em tempos compostos, tendo em conta ou o género do interlocutor ou o género do pronome de cortesia Lei (feminino), como podemos ver em (8) numa questão colocada a um interlocutor masculino:

(8) Paolo, (Lei) è andato/a al lavoro ieri?

Paolo, (Lei) essere-3asing. ido-masc/fem-sing. PP Adv?

2 Para uma análise pormenorizada de fenómenos de concordância das formas de cortesia, veja-se Comrie (1975). 
Nestas situações a norma do Italiano estabelece que a diferença é de natureza estilística: em contextos de maior formalidade, é mais habitual encontrar o particípio passado em concordância com o pronome de cortesia Lei do que com o género do interlocutor.

Inversamente, a concordância com o género do interlocutor não se faz com elementos pronominais em contextos formais. Serianni (1989:264) afirma que todos os elementos pronominais referentes à forma de cortesia Lei devem ser concordantes com a terceira pessoa do feminino singular. Ao que parece, no que diz respeito aos elementos pronominais, o valor de feminino da forma de cortesia é mais forte do que o género do interlocutor.

Em (9), o pronome de objecto directo (dir.) para a forma de cortesia é La (feminino) e, em (10), o de objecto indirecto (indir.) é Le (também feminino), independentemente do género do interlocutor.

(9) Paolo, La / chiamo domani. / Paola, La chiamo domani. Paolo, tu-formal-dir-fem. chamar- ${ }^{\mathrm{a}}$ sing. Adv. / Paola, tu-formal-dir-fem. chamar-1 ${ }^{\mathrm{a}}$ sing. Adv.

(10) Paolo, Le scrivo domani. / Paola, Le scrivo domani. Paolo, tu-indir-formal-fem. escrever- ${ }^{\mathrm{a}}$ sing. Adv. / Paola, tu-indir-formal-fem. chamar-1 ${ }^{\mathrm{a}} \mathrm{sing}$. Adv.

A utilização dos correspondentes pronomes masculino (com função de objecto directo e indirecto) não são considerados gramaticais na norma do Italiano, como se pode ver em (11).

(11) ^Paolo, Lo / chiamo domani. / *Paolo, Gli scrivo domani. $\star$ Paolo, tu-formal-dir-masc. chamar-1 ${ }^{\mathrm{a}}$ sing. Adv. / ^Paolo, tu-formal-indir-masc. escrever- $1^{\mathrm{a}}$ sing. Adv. 


\section{Perspectivas teóricas sobre as formas de CORTesia}

O sistema das formas de cortesia do Italiano standard possui um sistema que corresponde ao apresentado por Brown e Gilman (1960). Estes autores (1960:254) diferenciam as duas formas de cortesia usadas para nos dirigirmos a um interlocutor singular usando $T$ e $V$ (do latim $t \bar{u}$ e $\nu \overline{o s}$ ) e indicam, respectivamente, uma forma de cortesia informal e outra formal. Aparentemente Brown e Gilman, apesar de não o afirmarem de forma explícita, estarão a centrar a sua atenção na interacção entre elementos pronominais e a morfologia verbal. Usando a classificação de Brown e Gilman, a forma italiana $t u$ (e os elementos morfológicos de segunda pessoa do singular) corresponde a uma realização mais familiar, e portanto menos formal, enquanto que à forma italiana Lei (seguida de elementos morfológicos de terceira pessoa do singular) corresponde uma realização mais formal.

Seguindo a linha de pensamento de Brown \& Gilman (1960:252), os modos de tratamento estão associadas "with dimensions fundamental to the analysis of all social life - the dimensions of power and solidarity." Estas duas dimensões informam acerca da relação social que existe entre dois interlocutores e excluem-se mutuamente. De um ponto de vista linguístico, encontramos nesta afirmação de Brown e Gilman, a explicação para a utilização da forma $T$ por parte de um superior hierárquico ao dirigir-se a um subordinado e, consequentemente, um subordinado dirigir-se-á a um superior usando a forma $V$. De acordo com estes autores, o "poder" será o resultado de vários factores tais como "physical strenght, wealth, age, sex, institutionalized role of the church, the state, the army or within the family" (1960:255). O uso não recíproco de $T$ e $V$ encontra-se em sociedades altamente estruturadas e estratificadas. Entre pessoas da mesma classe, a forma de tratamento é recíproca embora socialmente distinta: nas classes elevadas a forma de trata- 
mento recíproca é $V$ enquanto que nas classes mais baixas a forma de tratamento é $T$. Tal como os autores referem (1960:257):

For many centuries French, English, Italian, Spanish, and German pronoun usage followed the rule of nonreciprocal $T-V$ between persons of unequal power and the rule of mutual $V$ or $T$ (according to social class membership) between persons of roughly equivalent power.

No entanto, como referem os autores, "not all differences between persons imply a difference in power" (1960:256). A diferença de poder causará uma falta de simetria entre os interlocutores, enquanto que as diferenças que não estão relacionadas com o poder são simétricas e, portanto, tendem a ser recíprocas. A "solidariedade" é o princípio que permite o reconhecimento recíproco de que o outro ocupa uma mesma posição na escala hierárquica. $\mathrm{O}$ exemplo clássico de uma relação baseada no "poder" seria a diferença de idade e exemplos de relação baseadas na "solidariedade" seriam, de acordo com os autores, frequentar a mesma escola, ter os mesmos progenitores, ou a mesma profissão (1960:258). Por exemplo, dois profissionais podem ter idades diferentes, mas o facto de partilharem a mesma profissão permite-lhes empregar formas de tratamento menos formais ao dirigirem-se um ao outro. Nestes casos, a forma de tratamento usada difere consoante o grau de "solidariedade": quanto maior for o grau de "solidariedade" mais facilmente se usam as formas $T$ e quando menor for o grau de solidariedade mais facilmente serão usadas as formas $V$.

Brown e Gilman foram os primeiros a analisar as formas de tratamento tendo em consideração aspectos sociológicos da interacção verbal e a pôr em evidência a maneira como a linguagem codifica factores sociológicos. Uma das conclusões que apresentam para as línguas românicas é que o 
"poder" é o factor que prevalece no emprego das formas de tratamento até ao século XIX e que a "solidariedade" começa a ganhar vantagem no século XX. No entanto, pode afirmar-se que as afirmações de Brown e Gilman não são de todo exaustivas relativamente às línguas românicas dado que o número de informantes que tiveram à sua disposição e o tipo de textos literários estudados foram muito limitados. ${ }^{3}$

No seu estudo sobre as formas de tratamento do Espanhol durante o Século de Ouro, Moreno (2002) conclui que a ideia de Brown e Gilman, segundo a qual o sistema de tratamento nas línguas europeias foi dominado pelos conceitos de "poder" até ao século XIX, é inaceitável. Moreno afirma claramente que "our data casts doubts on Brown and Gilman's assumptions that the power semantic was uncontested until the $19^{\text {th }}$ century, as the situation is not all that clear for Golden Age (16 ${ }^{\text {th }}$ and 17th century) Spanish." (2002:18).

Depois da explicação de Brown \& Gilman (1960), as formas de tratamento foram analisadas ainda por Lakoff (1973, 1977) e por Brown \& Levinson $(1978,1987)$. Em todos os casos, porém, a análise dos modos de tratamento inclui o fenómeno mais abrangente da cortesia em que as formas de tratamento são apenas uma parte. Lakoff (1977:79-106) afirma que a cortesia, entendida como uma função social da linguagem é algo que enforma qualquer escolha linguística feita por um falante. O sistema de cortesia seguirá, pois, três

3 "As primary evidence for the usage of the past we have drawn on plays, on legal proceedings, and on letters. We also have learned about contemporary usage from the literature but, more importantly, from long conversations with native speakers of French, Italian, German and Spanish both here and in Europe." (Brown \& Gilman 1960:253) Tal como os autores referem, os textos de carácter literário eram exclusivamente em língua inglesa e, relativamente ao italiano, referem ter usado onze (11) informantes. Ainda: para estudar a evolução dos sistemas das formas de tratamento nas línguas românicas, Brown e Gilman afirmam ter analisado "a small number os monographs and doctoral dissertations describing the detailed pronouns semantics for one or anothe language" (1960:253) continuando a afirmar que todos estes textos eram do início do século XX. 
regras: "distância" (distance), "deferência" (deference) e "camaradagem" (camaraderie). Estas três regras, segundo Lakoff (1977), não estão ordenadas hierarquicamente, mas constituem um conjunto de preferências individuais que é diferente para cada indivíduo.

Brown \& Levinson (1987) sugerem que os motivos que presidem à escolha das formas de cortesia residem na "distância” entre os interlocutores (uma relação simétrica), no "poder" dos interlocutores (uma relação assimétrica) e nas "imposições" que ameaçam a "imagem" (face) dos interlocutores num determinado contexto cultural (também definidos como "face threathening acts"). Este conceito de "imagem", definida com a imagem pessoal que cada falante crê ou deseja possuir quando intervém em público, indica que o uso de uma particular forma de cortesia é fruto da escolha pessoal do falante mediante uma determinada situação social.

Brown \& Levinson (1978, 1987) e Lakoff (1973, 1977) defendem que a escolha das formas de tratamento é pessoal e operada pelo falante. No entanto, não podemos esquecer que, sendo as formas de tratamento codificadas a nível morfológico, e existindo parte de um sistema linguístico partilhado por uma comunidade de falantes, a escolha das formas de tratamento não pode ser encarada como fundamentalmente pessoal e individual, pelo que é também condicionada por rotinas sociais, determinadas por hierarquias sociais.

\section{A evolução das formas de Cortesia no Italiano ATÉ AO SÉCULO XVI}

As línguas românicas possuem, grosso modo, duas formas pronominais utilizáveis quando um falante fala a um interlocutor: uma primeira, que em Italiano è o $t u$, usada em situações mais informais e de maior proximidade; uma segunda usada em situações mais formais onde estão envol- 
vidos uma maior distância social e um maior grau de formalidade, e que em Italiano è o Lei. As formas de tratamento das línguas românicas derivam do sistema das formas de tratamento do Latim. Segundo Brown e Gilman (1960), o Latim da antiguidade possuía somente uma realização: $t \bar{u}$ seguida de elementos morfológicos de segunda pessoa do singular. Inicialmente, forma plural $v \bar{o} s$ era usada em exclusivo para um interlocutor se dirigir ao imperador. Durante os tempos do império, o latim evoluiu para um sistema de duas formas de tratamento: $t \bar{u}$ e $v \overline{o s}$ seguidas, respectivamente, de elementos morfológicos de segunda pessoa do singular e do plural. Neste sistema a forma do plural $v \bar{o} s$ empregava-se para indicar uma maior distância social entre os interlocutores enquanto que $t \bar{u}$ indicava um tipo de relação mais próxima entre os interlocutores.

Contrariamente a Brown \& Gilman (1960), Niculescu (1974) defende que a evolução do sistema do Latim para o sistema das línguas românicas não se verificou de forma contínua. Niculescu afirma que na Idade Média a hierarquia eclesiástica foi responsável pela reintrodução das formas de tratamento latinas dos séculos VII e XIX (Niculescu 1974:78). Este autor esclarece ainda que a primeira ocorrência de elementos de segunda pessoa plural com intenção de indicar respeito aparecem em textos do século XII, mas defende ainda que é necessário analisar textos do século seguinte para encontrar uma oposição clara entre as duas formas.

Muitos outros autores defendem que nos séculos XII e XIII o sistema de formas de tratamento era condicionado por convenções sociais. Renzi (2002:272) nota que o uso do voi era recíproco na classe dominante tal como o uso de tu nas classes inferiores. Quando pessoas de classes sociais interagiam, o superior dirigia-se ao inferior usando o $t u$ e, por sua vez, recebia o voi. Coffen (2002:34) afirma que desde o aparecimento das línguas românicas e geralmente até ao 
fim da Idade Média, eram duas as formas de tratamento à disposição dos falantes, que para o Italiano seriam tu e voi, sendo a segunda usada para indicar um maior respeito ou uma maior distancia social do que a primeira.

Ao analisarmos as formas de tratamento, a problematização que surge é a de tentar perceber de que forma a ideia de pluralidade aparece ligada ao conceito de respeito. Jucker \& Taaivitsainen (2003:5) sugerem que "one possible explanation is that the plural is a metaphor in which size is taken to imply power and thus the use od a pronoun for a single addressee would ascribe power to this individual." Esta explicação estaria também, e de acordo com os mesmos autores, na base do uso do plural majestático, praticado pela realeza para falar de si mesma em vez da primeira pessoa do singular.

Brown e Gilman (1960) sugerem ainda que o pronome plural de respeito tem origem no facto de, a partir do século IV, o Império Romano se encontrar dividido em duas partes, apesar de ser uno sob o ponto de vista administrativo: o Império de Ocidente e o Império de Oriente, com Constantinopla e Roma como respectivos centros. Dado que cada parte do Império possuía o seu imperador, quando alguém se dirigia a um deles, esta pessoa dirigia-se de facto aos dois, pelo que daí derivaria o uso da forma plural. De qualquer modo, esta ideia não é muito aceitável, dado que o uso de um pronome plural para mostrar respeito a um interlocutor ocorre também em línguas não relacionadas com o Latim. ${ }^{4}$

Brown e Levinson (1987:198) apresentam duas outras possíveis explicações para o uso da segunda pessoa do plural como forma de tratamento formal. A primeira está associada à ideia de que o plural não identifica de forma unívoca o interlocutor. Isto é: o uso do plural é semelhante ao uso de formas nominais para nos dirigirmos a uma qualidade de um

${ }^{4}$ Brown \& Levinson 1987:198, cit. in Jucker \& Taavitsainen 2003:5. 
interlocutor em vez de nos dirigirmos directamente a ele ou a ela, tal como a forma Vostra Signoria do italiano antigo.

A segunda explicação de Brown e Levinson $(1987)^{5}$ defende que, com o pronome plural de tratamento, nos referimos não tanto ao indivíduo mas, por associação, ao grupo social ao qual o indivíduo pertence.

Migliorini (1957), noutra possível explicação para o uso do plural como forma de tratamento, refere a consequência directa da utilização do plural pelos imperadores:

Le allocuzioni astratte del tipo clementia tua, maiestas vestra si erano moltiplicate, com'è noto, già in età imperiale (il plurale allocutivo maiestas vestra era stato ricalcato sul plurale maiestatico maiestats nostra), e avevano continuato a fiorire nella cancelleria pontificia. (Migliorini 1957:187)

Para Niculescu (1974:90), no entanto, é no Trecento que as formas nominais de tratamento começam a aparecer juntamente com a noção de cortesia que emerge entre os séculos XII e XIV. Em vez de um pronome "si usano sostantivi astratti significando qualità presunte, attribuite all'interlocutore" (Niculescu 1974:90).

As formas nominais, como maiestas tuas, parece ter existido no Latim imperial mas era usada exclusivamente em relação ao imperador. Estas formas nominais, constituídas por um possessivo de segunda pessoa singular ou plural seguido por uma qualidade abstracta (tal como amplitudo, auctoritas, benignitas, celsitudo, eminentia, excellentia, experientia, felicitas, honestas, honorificentia, magnificentia, prudentia, entre outras), começaram a ser registadas com maior frequência. Além disso, estes honoríficos podiam ser seguidos por elementos de morfologia verbal tanto no singular como no plural. Um elemento que terá favorecido a generalização

${ }^{5}$ Citada em Jucker e Taavitsainen 2003:5. 
destas formas nominais de tratamento foi, segundo Niculescu (1974:91), a difusão do Cristianismo ao longo dos séculos IV e V. Estas formas nominais eram usadas na correspondência oficial e foram adoptadas pelas chancelarias dos finais da Idade Média.

Entre estas formas nominais, o substantivo mais usado no espaço italiano terá sido signoria e está relacionado com a ideia de poder do interlocutor. Tal como Niculescu refere, a forma de tratamento que contém signoria "è basata sul concetto di 'dominare', 'possedere' (signoria, signoreggiare, signoranza)" (Niculescu 1974:91. Ainda segundo Migliorini (1957), entre os séculos XIII e XV, esta forma de tratamento era utilizada só para alguém se dirigir "com particolare solennità a personaggi che esercitassero il potere" (Migliorini 1957:187). Enquanto forma nominal de tratamento, signoria co-ocorre com um possessivo e, tal como Migliorini defende, aparece mais frequentemente com o possessivo de segunda pessoa plural vostra do que com o singular tua. Dado que é usada para nos dirigirmos a pessoas em posição elevada na escala social, é compreensível que signoria ocorra em contextos em que são usados elementos morfológicos de segunda pessoa do plural. Ao usar formas nominais como vostra signoria, o falante evita dirigir-se directamente à pessoa do interlocutor através do uso de pronomes, o que aconteceria se usasse a forma voi.

Para contornar o uso explícito de voi, era possível usar formas nominais de tratamento. Em alguns casos, parece que certos elementos do discurso começam a concordar com o género feminino da qualidade, signoria, e não com voi, que era a forma de tratamento formal. Se o argumento da conversação fosse algo que pertencia ao interlocutor, em vez de usar, por exemplo, il vostro libro, começou a ser aceitável empregar il libro di vostra signoria; e, por conseguinte, em vez de realizar il libro di vostra signoria, alguém podia dizer il suo (di vostra signoria) libro por oposição a il vostro (di voi) libro. 
Será em contextos como este que, segundo Migliorini, (1957:188-189), começa a ser comum a utilização do acordo com a terceira pessoa do singular (e feminino).

O sistema do italiano contemporâneo, com a forma Lei seguida de elementos verbais e pronominais de terceira pessoa singular feminina, tem as suas origens nas formais nominais de tratamento. Uma vez que as formas nominais (os honoríficos) foram introduzidas e se generalizou a sua utilização (em vez de ser reservadas para indivíduos que desempenhavam de facto cargos de poder), segundo Migliorini existiam duas via alternativas:

(...) considerare la persona a cui ci si rivolge come una seconda persona plurale, e l'allocuzione [the nominal forms of address] come una perifrasi occasionale; o invece attenersi sempre alla forma allocutiva astratta, e concordare con essa tutti i pronomi al singolare femminile, tutti i verbi alla terza persona. (Migliorini 1957:188)

A característica de feminino da forma de tratamento formal Lei deriva das suas origens linguísticas. O Lei usado como forma pronominal de tratamento formal para um interlocutor singular é o resultado de um processo de pronominalização. A um certo ponto da evolução, as formas nominais como Vostra Signoria começaram a ser substituídas por pronomes como Quella e Ella e posteriormente por Lei. Todas estas formas pronominais têm em comum uma característica de feminino dado que pronominalizam o substantivo Signoria. E de formas nominais como Vostra Signoria, usadas como pronome sujeito, que nasce a forma Lei, a forma de tratamento formal do Italiano. ${ }^{6}$

${ }^{6}$ Migliorini não defende a teoria da origem espanhola da forma Lei. Afirma claramente que "la spinta culturale che ha prodotto l'espansione del Lei è indubbiamente spagnola, ma l'origine della forma e il modo stesso in cui essa si è cristallizzata sono in massima parte nostrani." (1957:196) 
É ainda Migliorini quem defende que o verbo na terceira pessoa do singular aparece mais frequentemente a partir do século XV. Antes disso, em contextos nominativos, a forma de tratamento usada era voi seguido por elementos de morfologia verbal de segunda pessoal do plural. Tal como Coffen afirma, o uso das formas indirectas de tratamento, como vostra signoria "caractérise le passage du Moyen Age aus Temps Modernes, sauf cependant pour le Français” (Coffen 2002:34)

\section{Conclusões}

A situação durante o século XVI parece ser mais complexa dado que o sistema das formas de tratamento não se articula só com duas realizações, $t u$ e $v o i$, mas sim com três: $t u$, voi e Vostra Signoria, bem como outras formas nominais de tratamento semelhantes. Com a generalização do uso das formas nominais, como Vostra Signoria, o sistema das formas de tratamento sofre um processo de reorganização interna em que, num primeiro período, compreensivelmente, existe coexistência de formas.

Os dados de que dispomos ${ }^{7}-$ e que nos propomos a apresentar mais sistematicamente no futuro - mostram que, no Cinquecento, as formas como Vostra Signoria (as formas nominais de tratamento) seguidas por elementos de morfologia verbal de terceira pessoa do singular são usadas ao mesmo tempo que voi (que selecciona elementos de morfologia verbal de segunda pessoa do plural). Além disso, existem casos em que o falante, numa mesma carta, se dirige ao seu interlocutor alternando voi e vostra Signoria, mas existem igualmente casos em que Vostra Signoria co-occorre com elementos morfológicos de terceira pessoa do singular e de segunda pessoa plural, característicos do uso de voi.

7 Parte destes dados está incluída na dissertação de M.A., elaborada sob orientação da Prof. Janice Aski, apresentada em Maio de 2005, na Ohio State University. 


\section{Bibliografia}

Brown, Penelope and Stephen C. Levinson. 1987. Politeness: Some universals in language usage. Cambridge: Cambridge University Press.

Brown, Roger and Albert Gilman. 1960. The pronouns of power and solidairy. In Language and social context. Org. de Pier Paolo Giglioli. London: Penguin Classics.

Coffen, Béatrice. 2002. Histoire culturelle des pronomes d'addresse. Vers une typologie des systèmes allocutoires dans le langues romanes. Paris: Honoré Champion Éditeur.

Comrie, Bernard. 1975. Polite plurals and predicate agreement. Language 51: 406-418.

Grand, Camille. 1930. "Tu, Voi, Lei». Etude des pronoms allocutoires italiens. Ingenbohl: P. Théodose.

Jucker, Andreas H. and Irma Taavitsainen. 2003. Introduction. In Diachronic perspectives on address forms system. Org. de Irma Taavitsainen and Andreas H. Jucker. Amsterdam/Philadelphia: John Benjamins.

Lakoff, Robin. 1973. The logic of politeness: Or, minding your p's and q's. Chicago Linguistic Society 9: 292-305.

Lakoff, Robin. 1977. Politeness, pragmatics, and performatives. In Proceedings of the Texas conference on performatives, presuppositions and implicatures. Org. de Andy Rogers, Bob Wal, and John P. Murphy. Arlington, VA: Center for Applied Linguistics.

Levinson, Stephen C.. 1995. Pragmatics. Cambridge: Cambridge University Press.

Migliorini, Bruno. 1957. I primordi del Lei. In Saggi Linguistici. Org. de Bruno Migliorini. Firenze: Le Monnier.

Moreno, María Cristobalina. 2002. The address system in the Spanish of the Golden Age. Journal of Pragmatics 34: 15-47.

Niculescu, Alessandro. 1974. Strutture allocutive pronominali reverenziali in italiano. Firenze: Olschki.

-. 1995. La deissi personale e il suo uso sociale. In Grande grammatica italiana di consultazione. Vol. III. Tipi di frase, deissi, formazione delle parole. Org. Lorenzo Renzi, Giampaolo Salvi, Anna Cardinaletti. Bolona: Il Mulino.

-. 2002. Tu e voi in italiano antico. In Roma et Romania. Festschrift für Gerhard Ernst zum 65. Geburtstag. Org. Sabine Heinemann, Gerald Bernhard, and Dieter Kattenbusch. Tübingen: Max Niemeyer Verlag.

Serianni, Luca. 1989. Grammatica italiana. Italiano comune e lingua letteraria. Torino: Utet. 